\title{
Diagnóstico do setor ferroviário brasileiro frente às expectativas com a renovação antecipada das concessões
}

\section{Diagnosis of the Brazilian rail sector with regards to expectancy of the early renewal of railway concessions}

\author{
Marina Donato $^{1 *}$, Fábio Santos Cerbino ${ }^{1}$, Isaias Pereira Seraco ${ }^{1}$, Hostílio Xavier Ratton Neto ${ }^{1}$
}

\section{RESUMO}

Este artigo trata das possíveis alternativas para a alteração da configuração atual do transporte de cargas por ferrovia no Brasil, tipicamente caracterizado pela movimentação de commodities destinadas à exportação e limitado quanto aos objetivos de integração nacional e de atendimento ao mercado interno. Foram abordadas as perspectivas do futuro deste modo no Brasil e quais os impactos, não só sobre o sistema de transporte, como sobre a atividade econômica do qual ele faz parte, principalmente frente às propostas de renovação antecipada das concessões. Foram analisadas as propostas até o momento negociadas, bem como iniciativas independentes por parte do legislativo visando atualizar o marco regulatório do setor. Buscou-se estimular o debate sobre o benefício econômico para o Brasil do modelo de concessões vigente, bem como a possibilidade de flexibilização do mercado permitindo a competitividade e a abertura aos operadores independentes.

Palavras-chave: Ferrovia; Concessão; Renovação.

\begin{abstract}
This paper assesses the possible alternatives for changing the current framework of freight transportation railroad network in Brazil, which is typically characterized by the transportation of commodities destined to exportation and also a limited view in terms of national integration objectives and the internal market. The prospects of the railways future in Brazil were discussed and also its impacts on the economic activity - not only on the transport system - especially in relation to the proposals for the early renewal of concessions. The proposals hitherto negotiated were analyzed, as well as independent initiatives by the brazilian congress which aimed at updating the regulatory framework of the rail sector. The objective is to debate the economic benefits of the current concession model, as well as the alternatives to promote competitiveness and the opportunities to independent operators in the Brazilian rail market.
\end{abstract}

Keywords: Railway; Concession; Renewal.

\section{INTRODUÇÃO}

Após cerca de 20 anos do término do processo de privatização das ferrovias brasileiras, o País retoma a discussão sobre o plano de gestão desse ativo, motivado

\footnotetext{
${ }^{1}$ Programa de Engenharia de Transportes (PET - COPPE), Universidade Federal do Rio de Janeiro.

*E-mail: donato@pet.coppe.ufrj.br
} 
principalmente pelo movimento das atuais concessionárias pela antecipação da renovação das concessões. Esse processo, adotado no fim da década de 1990, transferiu a operação do transporte e a manutenção das linhas ferroviárias à iniciativa privada, sendo que, na época, a malha nacional se encontrava em más condições de operação.

Comparando as condições operacionais e estruturais das vias férreas que as concessionárias tiveram que administrar no início das concessões com o estado atual, são observados avanços significativos, porém, quando o diagnóstico avança para dados mais detalhados, a perspectiva se modifica, principalmente no que se refere ao tipo de serviço prestado pelas ferrovias e pela taxa de utilização das linhas. Com relação aos produtos transportados, aproximadamente $81 \%$ do volume total de mercadorias é relativo ao transporte exclusivamente de minério de ferro, e quanto à operação das linhas, apenas $24 \%$ estão em plena operação (PNL, 2018).

Face a tal contexto e tendo em vista que as atuais concessionárias ferroviárias têm se adiantando com o pedido de renovação de suas concessões, é imperante discutir os modelos de concessão e de regulação do transporte ferroviário nacional, visando avaliar as implicações da extensão do atual cenário por mais 40 anos. Assim, o presente trabalho tratou do contexto atual de operação das ferrovias nacionais e das propostas de renovação antecipada das concessões, bem como o possível impacto dessas propostas no desenvolvimento da malha nacional e na diversificação dos produtos transportados. Este trabalho estimula o debate sobre o benefício econômico para o Brasil do modelo de concessões vigente, sendo relevante, sobretudo no que se refere à oportunidade que se vislumbra, neste momento, de alterar os termos das concessões para se proporcionar a possibilidade de flexibilização do mercado de operações ferroviárias.

\section{AS PRIVATIZAÇÕES FERROVIÁRIAS BRASILEIRAS}

O contexto histórico que levou ao processo de privatização das ferrovias nacionais é complexo, perpassando uma série de questões políticas e econômicas, contudo, de maneira simplificada, cabe destaque para as últimas décadas da administração estatal, que foram marcadas por poucos investimentos e que culminaram em um sistema estagnado no que se refere à sua expansão geográfica e de mercado. Houve exceções, como a implantação da Estrada de Ferro Carajás e os projetos da Ferrovia Norte-Sul e Ferronorte (PEIXOTO, 1977; KATINSKY, 1994), contudo, principalmente durante as décadas de 1980 e 1990, a ausência de investimentos abrangentes manteve a malha deficitária, sem modernizações expressivas, com muitos 
trechos, inclusive, sendo desativados. Nesse contexto, a política de concessões adotada pelo Governo Federal na segunda metade da década de 1990, especificamente com relação à privatização das ferrovias, teve como objetivo atrair investimentos para a recuperação e modernização do sistema, e assim aumentar a participação e a qualidade do serviço (CASTRO e LAMY, 1994; BNDES, 2019).

A Lei n $8031 / 90$ instituiu o Programa Nacional de Desestatização, sendo a RFFSA nele incluída em 10/03/1992. O primeiro passo foi reorganizar as doze superintendências da RFFSA em seis malhas: Nordeste, Oeste, Centro-leste, Sudeste, Teresa Cristina e Sul. Cada malha regional passou a constituir uma unidade de negócio independe e autossuficiente. As malhas foram leiloadas entre 1996 e 1998, pelo prazo de concessão de 30 anos, podendo ser prorrogado pelo mesmo período. Para atrair as empresas, o modelo não exigia nenhum investimento pré-definido. Desse modo, para que as metas fossem atendidas, as concessionárias eram livres para decidir como investir na malha sob sua administração (SOUSA e PRATES, 1997). Foram definidas duas metas de desempenho para acompanhar a qualidade da prestação de serviço por parte das concessionárias. As malhas ferroviárias deveriam aumentar o volume transportado e reduzir os acidentes, determinadas de acordo com as especificidades de cada malha e o desempenho operacional projetado. Apesar de não haver nenhuma imposição formal de investimento, era esperado um grande volume para a recuperação dos trechos e modernização dos ativos operacionais (SOUSA e PRATES, 1997; BNDES, 2019; DNIT, 2019). Na Tabela 1, são apresentadas as concessionárias com as respectivas malhas há época do processo de concessão.

Além dessas, o governo outorgou a concessão da Ferrovia Vitória a Minas EFVM e da Estrada de Ferro Carajás - EFC para a Companhia Vale do Rio Doce. Outras empresas de caráter mais local também foram concedidas, sendo elas a Ferrovias Norte Brasil S.A. - FERRONORTE; Estrada de Ferro Mineração Rio do Norte; Estrada de Ferro Jarí; Estrada de Ferro Trombeta; Estrada de Ferro Votorantim; e Estrada de Ferro Paraná Oeste S.A. - FERROESTE. Para fiscalizar as concessionárias e resolver problemas de caráter administrativo entre elas, usuários e o Estado, foi criada a ANTT Agência Nacional de Transportes Terrestres. 
Tabela 1 - Concessionárias ferroviárias constituídas no processo de privatização

\begin{tabular}{ccccc}
\hline $\begin{array}{c}\text { Malhas } \\
\text { Regionais }\end{array}$ & $\begin{array}{c}\text { Data do } \\
\text { Leilão }\end{array}$ & Concessionárias & $\begin{array}{c}\text { Início da } \\
\text { Operação }\end{array}$ & $\begin{array}{c}\text { Extensão } \\
(\mathbf{k m})\end{array}$ \\
\hline Oeste & 05.03 .96 & Ferrovia Novoeste S.A. & 01.07 .96 & 1.621 \\
\hline $\begin{array}{c}\text { Centro- } \\
\text { Leste }\end{array}$ & 14.06 .96 & Ferrovia Centro-Atlântica S.A. & 01.09 .96 & 7.080 \\
\hline Sudeste & 20.09 .96 & MRS Logística S.A. & 01.12 .96 & 1.674 \\
\hline $\begin{array}{c}\text { Tereza } \\
\text { Cristina }\end{array}$ & 26.11 .96 & Ferrovia Tereza Cristina S.A. & 01.02 .97 & 164 \\
\hline Sul & 13.12 .96 & ALL-América Latina Logística do Brasil \\
\hline Nordeste & 18.07 .97 & Companhia Ferroviária do Nordeste & 01.03 .97 & 6.586 \\
\hline Paulista & 10.11 .98 & Ferrovias Bandeirantes S.A. & 01.01 .98 & 4.238 \\
\hline \multicolumn{5}{c}{ Total } \\
\hline \multicolumn{5}{c}{ Fonte: ANTT (a) (2019) } \\
\hline
\end{tabular}

\section{A OPERAÇÃO DAS CONCESSIONÁRIAS}

O processo de privatização foi responsável por uma significativa melhora nos indicadores de desempenho do setor ferroviário nacional. Os investimentos realizados pelas concessionárias permitiram que o setor, que há muito estava em estagnação, retomasse o crescimento com incremento do volume de carga transportado. Em uma análise dos últimos anos de operação é possível destacar quatro fases marcantes até o ano de 2015 (ASSIS et al., 2017):

1. De 1997 a 2003, enquanto o PIB do País cresceu à taxa média de $1,70 \%$ ao ano (a.a.), a produção de transporte das ferrovias teve crescimento médio de $4,69 \%$ ao ano (a.a.) e o investimento real das concessões registrou decréscimo médio de 0,37\% a.a., comparado ao valor investido em 1997 (preços constantes). $\mathrm{O}$ aumento mais do que proporcional da produção se justifica por diversas melhorias operacionais e ganhos de produtividade após anos de escasso investimento na ferrovia no período pré-concessão;

2. De 2003 a 2008, o PIB evoluiu em 4,81\% a.a., o investimento real das concessões cresceu à taxa média de $23,11 \%$ a.a. e a produção de transporte aumentou 7,89\% a.a.. Foram anos de expansão da capacidade do sistema ferroviário, principalmente por meio da aquisição de material rodante;

3. No período de 2008 a 2013, os investimentos escassearam novamente, em decorrência da crise internacional, decrescendo 2,36\% a.a. sobre a base de 
2008. A produção cresceu à taxa de 2,23\% a.a., enquanto o PIB evoluiu à taxa anual de $3,22 \%$. Cabe destaque ao período de 2011 a 2013, quando as indefinições sobre o novo marco regulatório ferroviário contribuíram para que os investimentos arrefecessem, produzindo, por consequência, certa estagnação na produção do setor.

4. Nos dois anos subsequentes, de 2013 a 2015, enquanto o PIB decresceu, na média, 1,89\% a.a., os investimentos reais cresceram 5,77\% a.a. e a produção evoluiu à taxa de 5,50\% a.a.. Os investimentos concentraram-se no aumento de capacidade de exportação de minérios na Estrada de Ferro Carajás (EFC) e no projeto de expansão da VLI Logística (subsidiária da empresa Vale dedicada à carga geral).

Assis et al. (2017) salientam que em praticamente todo o período analisado o crescimento do transporte esteve maior que o crescimento do próprio PIB. A tendência geral, portanto, foi de crescimento acentuado, como pode ser evidenciado na Figura 1, na qual se apresenta a evolução do transporte no período de 2006 a 2018, em toneladas úteis transportadas.

Figura 1 - Evolução do transporte ferroviário em toneladas úteis $\left(\mathrm{x} 10^{3}\right)$

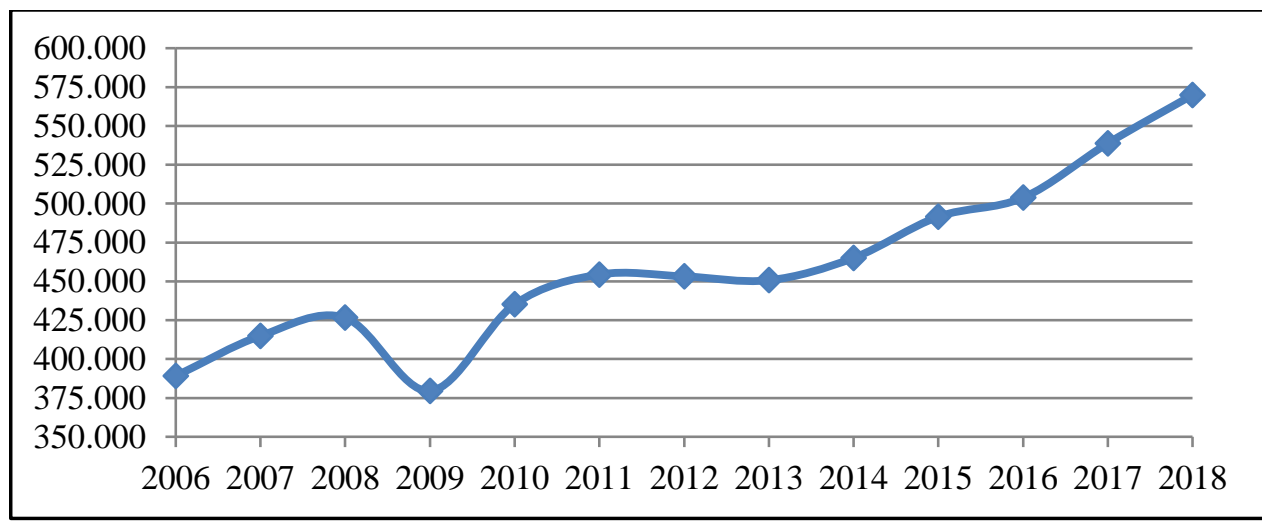

Fonte: ANTT (c) (2019)

Os investimentos no período tiveram comportamento muito semelhante, justificando, portanto, a evolução do volume transportado (ANTT (c), 2019). Com relação à segurança, também ocorreu melhora dos indicadores, com a queda do índice de acidentes, de 578 ocorrências por milhão de trem.km em 2006, para 207 ocorrências por milhão de trem.km em 2016. Esses indicadores mostram, quantitativamente, que ocorreu melhora nas condições de transporte. Porém, ao buscar outros indicadores, de 
caráter mais qualitativo, percebe-se que o transporte evoluiu de certa forma, monopolizado, em segmentos bastante restritos. Esse fato pode ser constatado ao se analisar os tipos de mercadorias transportadas. Segundo dados da ANTT (c) (2019), dos 569 milhões de toneladas úteis transportados em 2018, 81\% desse valor, cerca de 458 milhões de toneladas, são referentes ao transporte de commodities minerais, e, além disso, do restante de mercadorias, $10 \%$ é relativa às commodities agrícolas, como grãos e farelo. Nos aproximados $10 \%$ restantes, a indústria cimenteira e siderúrgica representam o maior volume. A carga geral conteinerizada ou não, responde, no seu conjunto, por menos de 0,5\%. Essa conformação, contudo, não é característica recente, já que, na Figura 2, é possível ver que o transporte de commodities está há muito consolidado e se intensificando no cenário ferroviário nacional, haja vista a queda da participação da carga geral, e praticamente a estagnação da participação do transporte de contêineres.

Esses dados indicam que os investimentos por parte das concessionárias foram focados no aprimoramento do atendimento a um grupo específico de clientes, que, por se tratarem de mineradoras e produtores agrícolas, praticamente passaram a utilizar as ferrovias como sistemas dedicados de exportação, ou seja, as linhas formaram corredores diretos entre produtores e portos. É pertinente ainda aliar a este contexto as informações levantadas pela Revista Ferroviária (2019), que indicam que 58\% da malha ferroviária nacional está praticamente sem uso, sendo que destes, cerca de 6 mil quilômetros estão subutilizados e 12 mil quilômetros estão completamente inoperantes.

Pela conjunção dos dados, deduz-se que as empresas concentraram investimentos apenas nos trechos cuja demanda é maior, paralisando as operações naqueles cujo tráfego seria menor, e, a julgar pela composição de mercadorias transportadas, é possível supor que estes trechos teriam caráter regional, com cargas de pequeno volume e atendendo demandas internas do País. Outro aspecto importante diz respeito ao direito de passagem, que permitiria que empresas explorassem demandas pulverizadas em trechos de outras concessionárias. Segundo dados da ANTT (c) (2019), dos 407 bilhões de TKU (toneladas-quilômetro úteis) produzidas em 2018, cerca de 40 milhões se configuraram como de tráfego mútuo ou direito de passagem, respondendo, portanto, por muito menos de $0,01 \%$ da produção de transporte. 
Figura 2 - Evolução do transporte de carga por tipo de mercadoria

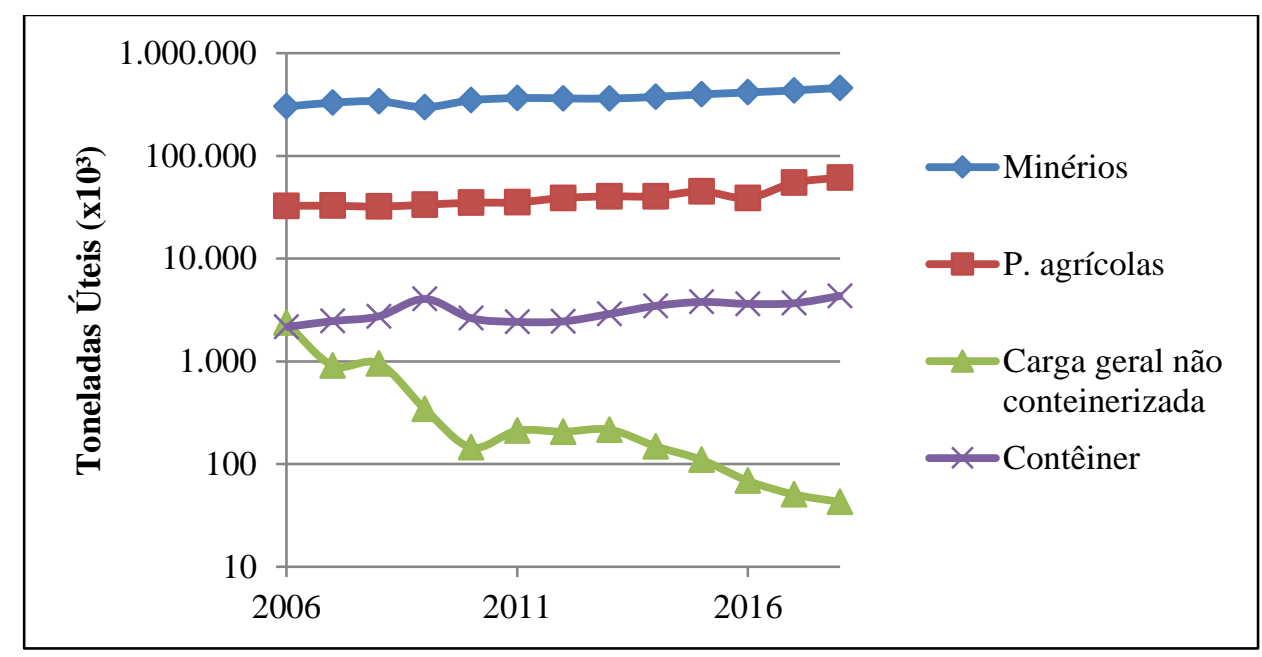

Fonte: ANTT (c) (2019)

\section{A BAIXA DIVERSIFICAÇÃO DE CARGAS E OS TRECHOS ABANDONADOS}

Os motivos que levaram as companhias a adotarem esse tipo de operação não são claros. Em Assis et al. (2017), são elencadas algumas possíveis causas da situação, como geometria deficiente; escassez de oferta/demanda, fato este acentuado pelo abandono de linhas regionais; baixa velocidade média comercial, de cerca de $16 \mathrm{~km} / \mathrm{h}$; e baixa competição intramodal.

É relevante destacar que a composição acionária das quatro principais companhias do País também dá indícios de que o transporte é guiado pelas demandas internas corporativas, ou seja, as mineradoras buscam assegurar a exportação de seus produtos, e, da mesma forma com os produtos agrícolas. A demanda restante é captada conforme a possibilidade e a ociosidade resultantes da sazonalidade do mercado de commodities.

Ao longo dos anos de operação, em função da dinâmica de mercado, ocorreram mudanças no que se refere à estrutura das concessionárias que originalmente participaram do processo de privatização. As malhas Oeste, Sul e Paulista, bem como a antiga Ferronorte, foram absorvidas pelo grupo Rumo Logística, atual responsável pela operação nessas linhas. Já a Ferrovia Centro Atlântica passou a ser administrada pela Holding VLI Logística, que explora também, por meio de direito de passagem, as malhas da EFVM e EFC (ANTT (b), 2019). Assim, dentre as diversas concessionárias, é possível destacar quatro de maior relevância nacional, em função principalmente da movimentação de mercadorias, mas também pela abrangência e localização das malhas, sendo elas MRS, VLI, aquelas operadas pela mineradora Vale (EFVM e EFC), e Rumo. 
Dessas quatro principais, três possuem composição acionária majoritariamente formada por mineradoras e siderúrgicas, como visto a seguir:

- MRS: Minerações Brasileiras Reunidas S.A. - MBR (32,9\%), Companhia Siderúrgica Nacional - CSN (18,6\%), CSN Mineração (18,6\%), Usiminas Participações e Logística - UPL (11,1\%), Vale $(10,9 \%)$, Gerdau $(1,3 \%)$ e um grupo pulverizado de pequenos investidores (6,5\%) (MRS, 2019);

- VLI: Vale (37,6\%), Brookfield (26,5\%), Mitsui (20\%), e FI-FGTS $(15,9 \%)(V L I, 2019)$;

- Vale: Litel/Litela (21\%), Bradespar (5,7\%), Mitsui\&Co (5,6\%), BNDESPar (6,3\%), investidores brasileiros não identificados (15\%), e investidores estrangeiros não identificados (46,4\%) (VALE, 2019).

Essa composição reflete decisivamente no tipo de carga comumente transportado por essas empresas, mais de 80\% minérios (ANTT (b), 2019). Quanto à Rumo, sua composição acionária tem a seguinte configuração: Cosan Logística S.A. (28,47\%), Julia Arduini $(3,82 \%)$, Administradores $(0,12 \%)$, Tesouraria $(0,00 \%)$ e Free Float (67,59\%). Da mesma maneira, sendo o grupo Cosan explorador do agronegócio, essa característica também se reflete sobre o transporte, cujo maior volume transportado pela companhia consiste em commodities agrícolas (ANTT (b), 2019; RUMO, 2019).

A conformação atual da malha também prejudica o atendimento de outras cargas. Como os trechos e ramais regionais foram desativados ao longo do tempo, as linhas alimentadoras que seriam responsáveis por buscar e distribuir as cargas gerais nos produtores e consumidores não estão mais disponíveis, dificultando a chegada e distribuição dos produtos. A ausência de terminais intermodais também prejudica o desenvolvimento de soluções de transporte mais eficientes e competitivas. Em função desse contexto, as linhas remanescentes que continuam em operação, são basicamente trechos troncais de ligação entre minas e portos, ou então entre grandes armazéns e portos, sem estruturas intermediárias dedicadas ao serviço intermodal de pequeno porte, nesse caso referindo-se à carga geral, praticamente inviabilizando, desse modo, a captação de mais tipos de cargas.

\section{RENOVAÇÃO ANTECIPADA DAS CONCESSÕES}

Diante das dificuldades enfrentadas pela política de construção de novas ferrovias e da intensidade da crise fiscal enfrentada pelo País, o foco da política de 
transporte ferroviário nacional se deslocou para a retomada do investimento tendo como base a prorrogação antecipada dos contratos vigentes. Nesse sentido, a Resolução PPI 42/2018 definiu elementos centrais para a reestruturação do Subsistema Ferroviário Federal, com destaque à prorrogação antecipada de contratos de concessão como medida para viabilização de novos investimentos, principalmente por meio da transferência dos recursos advindos da outorga das concessões para a construção de novos projetos. Como exemplos desses projetos, podem ser citados a Ferrovia EF-354 GO/MT/RO (Ferrovia de Integração do Centro-Oeste - FICO), e o Contorno Ferroviário - Ferroanel Norte de São Paulo.

As antecipações das renovações, no entanto, podem adquirir relevância não meramente por viabilizar investimentos no setor, mas também por se configurarem como um momento propício para a promoção de mudanças decisivas nas características do transporte ferroviário nacional face ao modelo de operação visto nas últimas décadas de operação privada, visando ao aprimoramento e modernização das ferrovias. Nesse tocante, podem ser destacados três aspectos básicos que estão a nortear os questionamentos: o modelo de operação das concessões; questões ligadas ao direito de passagem; e o encolhimento da malha fruto da desativação de trechos de pequena envergadura.

No que tange ao modelo de operação das concessões, a partir de 2015, retomouse a ideia de concessões verticalmente integradas nas ferrovias, deixando de lado o modelo proposto anteriormente apresentado em 2012, no qual o poder público concedente encamparia toda a malha e venderia o direito de passagem. Assim, agora, as atuais concessionárias teriam seus contratos prorrogados em vistas a viabilizar investimentos e ampliação de capacidade.

Adicionalmente, a antecipação permitiria a arrecadação de outorga pelo poder concedente. Com a alocação de maiores montantes para a ampliação de capacidade e redução de conflitos urbanos, o resultado natural seria benefícios tanto de ordem social como econômica. A crítica acerca do retorno ao modelo vertical e prorrogação das atuais concessões é decorrente do engessamento do mercado ferroviário nos mesmos players, sem a possibilidade de promover a concorrência tão almejada no modelo proposto anteriormente. Entretanto, os benefícios advindos das prorrogações poderiam ser maiores que a promoção de novas licitações. Com isso, a prorrogação antecipada dos contratos permitiria tanto a inclusão da obrigatoriedade dos investimentos nos 
contratos de concessão quanto a atualização de cláusulas contratuais. Considerando a economicidade dos atos administrativos, nos termos do art. 70 da Constituição, a prorrogação antecipada tem sido mostrada como a alternativa que melhor se adequa e atende ao interesse público.

Na sequência das discussões sobre a antecipação das concessões, o segundo ponto de debate se destaca principalmente pela possibilidade de se colocar em seu bojo a prioridade pelo direito de passagem. No entanto, a limitação ou a indisponibilização de capacidade da malha para trens de outros operadores são um óbice de difícil superação. Por conta disso, o terceiro ponto na discussão sobre as antecipações das renovações envolve o uso da totalidade da malha concedida e a flexibilização do sistema em vistas a atrair novos investidores. Nesse tocante, o que se vislumbra é a promoção do desenvolvimento das short-lines e da atuação dos operadores ferroviários independentes (OFIs).

Conceitualmente, short-lines são vias férreas de menor extensão, conectadas às redes ferroviárias de maior alcance, operadas por meio de contratos de concessão. Enquanto as grandes ferrovias nacionais funcionariam como vias troncais, estruturantes do sistema logístico nacional, as short-lines seriam vias arteriais, alimentadoras (originadoras, desembocaduras, integradoras, transferidoras) dos grandes sistemas de transporte. Em decorrência de sua menor extensão, são muitas as características atrativas sob o ponto de vista do investidor:

- Menor complexidade para estruturação, exigindo menores porções de terra para implantação; menor complexidade de licenciamento ambiental; menores investimentos para implantação e prazos menores para retorno econômico-financeiro;

- Maior capilaridade, o que garantiria novas cargas para o sistema logístico;

- $\quad$ Possibilidade de diversificação na matriz de transportes, com aumento da quantidade de carga transportada e dos diversos perfis que poderiam ser atendidos;

- Incremento no sistema, com potenciais para transportes de passageiros e para exploração turística;

- $\quad$ Aumento do interesse privado na exploração de ativos setoriais, tendo em vista os diversos tipos de ferrovias que seriam passíveis. 
Além disso, as short-lines se apresentariam como alternativa à desativação de trechos ferroviários. Isso seria relativamente simples: ao invés de desativar certo trecho, as concessionárias ou o poder concedente poderiam realizar chamada pública para interessados na sua exploração. Produtores locais de determinado tipo de commodity, cooperativas, indústrias, associações de usuários, dentre outros agentes, poderiam ter interesse na operação desse trecho, evitando, assim, sua desativação.

Segundo tal perspectiva, o PLS 261/2018, propõe que ferrovias construídas ou adquiridas pela iniciativa privada poderiam ser exploradas em regime de direito privado, por meio de outorga seguinte ao processo de chamada ou anúncio público. A autorizatária promoveria os investimentos necessários para a criação, a expansão e a modernização das instalações ferroviárias por sua conta e risco (art. 15, § $1^{\circ}$ tendo direito ao regime de liberdade de tarifas, que seriam comunicadas ao regulador competente antes de ser praticadas (art. 16). Esse modelo proporcionaria a existência de ferrovias estruturantes do sistema logístico interno, não necessariamente voltadas para a exportação, e teriam a virtude de ampliar a capacidade do setor. Assim, as short-lines serviriam para:

- Contribuir na reabilitação do sistema ferroviário nacional para atender às demandas do comércio interestadual e de defesa nacional;

- Reformar a política regulatória federal de modo a dispor-se de um sistema ferroviário mais seguro e eficiente;

- Contribuir para aumentar a viabilidade da permanência do sistema ferroviário no setor privado da economia;

- $\quad$ Estabelecer processo regulatório que equilibrasse as necessidades dos embarcadores, transportadores e do público;

- Contribuir para a reabilitação e financiamento do sistema ferroviário.

\section{ANÁLISE E DISCUSSÕES}

Tomando como base a evolução dos indicadores do transporte ferroviário nacional depois da transferência de sua exploração para concessões privadas, evidenciase, uma melhora significativa quanto ao volume transportado, à redução de acidentes e o desenvolvimento tecnológico. Esses números, isolados, representam um cenário bastante positivo, porém quando o diagnóstico avança para dados mais detalhados, o cenário se modifica, principalmente no que se refere ao tipo de serviço prestado pelas ferrovias e pela taxa de utilização das linhas. Isso, porém, não é um fenômeno recente, 
pois a matriz de produtos transportados pelas ferrovias se alterou pouco desde então. $\mathrm{O}$ minério de ferro, que na RFFSA respondia por cerca de $43 \%$ do movimento no transporte, continuou sendo o principal produto transportado e teve sua relevância acentuada, já que a proporção em relação ao volume total aumentou para cerca de $80 \%$ do volume movimentado de mercadorias. Já a taxa de utilização das linhas sofreu redução significativa, pois dos 30 mil quilômetros concedidos, pouco menos de um terço é plenamente utilizado.

O que se põe em discussão é a ausência de instrumentos regulamentares e de mecanismos capazes de tornar o transporte ferroviário mais acessível para outros setores produtivos. Se essa abertura não acontecer, as rodovias continuarão a ser a sua mais importante, senão a única, via para escoamento. Tal dependência envolve o risco de se ter a repetição de greves, como a ocorrida em maio de 2018, promovida pelos motoristas do transporte rodoviário.

A criação de condições mais eficazes para favorecer o direito de passagem de operadores ferroviários independentes pela malha concedida às atuais concessionárias pode ser a solução para conciliar interesses e objetivos. A desativação de trechos ferroviários é resultado do modelo de concessões adotado, que entregou malhas de grande extensão e de diversas envergaduras. Com tal enfoque, as atividades se concentraram onde se tinha maiores rendimentos, e as demais linhas foram paralisadas ou continuaram sem oferta de serviços, o que culminou com mais de dois terços da malha nacional sendo fechada ou subaproveitada.

Essas duas características essenciais, atendimento exclusivo a um segmento e desativação de trechos, fomentam a proposta de modernização das concessões, pelo fato de que as empresas tentam a antecipação da renovação de seus contratos. De maneira geral, dentre as medidas discutidas como compensação ou pagamento pela renovação antecipada, estão o investimento cruzado, em que os recursos da renovação de uma concessão são destinados para melhora ou construção de novos trechos; a aplicação de parte do montante dos recursos da renovação na própria malha objeto da renovação, com a modernização e melhoramento da estrutura atual; e com relação aos trechos de baixo movimento abandonados, a devolução a união mediante pagamento de indenização pelo estado da linha.

A primeira renovação antecipada foi a da Malha Paulista, pela empresa Rumo Logística, na qual, não ficou evidente o que seria feito com os trechos sem tráfego. Com 
efeito, os trens da própria companhia continuarão sendo tratados prioritariamente e os montante de investimentos negociados na renovação continuaria concentrado na própria malha em uso, modernizando-a de maneira a aumentar a capacidade de transporte, que está aquém do volume de commodities agrícolas produzido no Centro-Oeste, sua maior clientela. Nesse contexto permanecem as mesmas condições vigentes, sem definição do destino dos trechos abandonados.

Consulta pública e análises posteriores conduziram a modificações além de melhoramentos nos corredores principais (duplicação, construção de pátios de cruzamento e ampliação de outros; obras para a mitigação de conflitos urbanos) para as demais renovações. Está prevista a possibilidade de devolução de ramais sem utilização ao poder concedente, e a definição de regras para o direito de passagem. Também foi cogitada a possibilidade de investimento cruzado, já que o governo federal não dispõe de recursos financeiros para viabilizar a construção de novos trechos. Nessa modalidade, os novos trechos ferroviários seriam construídos por meio da outorga paga pelas concessões renovadas.

No entanto, as ferrovias previstas para serem construídas pelo valor de compensação obtido pelo investimento cruzado, a FICO - Ferrovia de Integração Centro-Oeste - e o Ferroanel de São Paulo, são destinadas, a primeira para o transporte de commodities agrícolas produzidas no estado do Mato Grosso, e a segunda, visa à separação do tráfego ferroviário de cargas das linhas de passageiros no entorno da cidade de São Paulo. Além disso, projetos independentes de concessões, como a FIOL Ferrrovia de Integração Oeste-Leste - e a própria Ferrovia Norte-Sul, também mantêm o perfil voltado para o transporte de commodities. $\mathrm{O}$ atendimento ao tráfego interestadual de mercadorias não parece estar previsto, embora não seja impossível executá-lo tendo em vista que os traçados previstos para as obras citadas atravessam polos importantes de produção e consumo. A flexibilização do transporte, no que se refere a mercadorias em geral, ainda parece distante. Não se prevê construção de terminais intermodais e as novas implantações de ferrovias têm foco ou na agroindústria ou na substituição de trechos com traçado urbano. O direito de passagem, por si só, não garante que ocorra diversificação do transporte e a falta de detalhamento quanto aos trechos abandonados ainda faz persistir a dúvida quanto ao seu destino.

A partir, portanto, das linhas gerais que estão a nortear os termos das antecipações das renovações, não há indícios de que a dinâmica do transporte visto 
atualmente se altere significativamente com a efetivação das renovações. Não se discute o mérito de empresas ferroviárias terem liberdade de atender ao mercado que lhes é mais atraente e lucrativo. Isso seria plenamente compreensível se as ferrovias fossem completamente privadas, o que não é caso do Brasil. As concessionárias são detentoras do direito de exploração de uma rede que é pública, e como tal, deveria ter foco no benefício da sociedade que, em linhas gerais, foi a sua financiadora. Desse modo, a renovação das concessões precisa contemplar pontos que foram ignorados anteriormente.

No que se refere ao abandono de trechos, a legislação poderia favorecer o livre acesso aos trechos de menor interesse por empresas de pequeno porte. Não se trata de tráfego mútuo, mas de permitir que esses trechos sejam operados por empresas menores, que, com suas estruturas empresariais de menor porte, poderiam lucrar com o transporte em menor escala. Além disso, como esses trechos, em sua grande maioria, estão ligados às linhas troncais, essas empresas seriam alimentadoras das grandes ferrovias, atenderiam demandas regionais e fariam a distribuição das mercadorias localmente. Com isso, a participação do modo ferroviário na matriz modal de transporte seria ampliada.

Para tanto, além dos termos discutidos na antecipação das concessões, seria necessária uma atualização do marco regulatório do setor ferroviário, facilitando o acesso de pequenas empresas privadas à operação de trechos de baixa envergadura, e, ainda permitir que o tráfego local de cargas gerais tenha acesso ao sistema de maior porte, garantindo-lhes janelas para a passagem de suas composições na grade horária das concessionárias. Além disso, permitir que empresas privadas arquem com a construção e operação de ferrovias particulares também seria uma forma de permitir que o sistema ferroviário nacional se desenvolvesse, garantindo livre acesso das empresas ao mercado, inclusive com a construção de ramais secundários para atender uma cidade ou então um cliente específico.

\section{CONCLUSÃO}

Ainda que haja recomendações para ratificação do modelo de integração vertical e desintegração geográfica das concessões ferroviárias brasileiras, voltadas majoritariamente para o transporte de cargas destinadas à exportação, acredita-se que este não constitui o caminho para o alcance dos objetivos de integração nacional e atendimento ao mercado interno com vistas ao fortalecimento e ao desenvolvimento 
econômico do Brasil. Além disso, a manutenção do modelo vigente perpetua a dependência das ferrovias e do próprio País, de um mercado de transporte suscetível às oscilações do mercado externo e globalizado de commodities, sem a indução do desenvolvimento de um mercado interno integrado e consolidado, capaz de permitir uma melhoria da capacidade de gerenciamento governamental em situações de crise econômica.

A pequena quantidade de empresas presentes na exploração das ferrovias favoreceu a situação oligopolista, limita a concorrência no mercado, e induziu a formação de monopólios regionais, de modo que a infraestrutura ferroviária é utilizada, quase que exclusivamente, para o transporte das cargas dos controladores das concessões, como extensão de sua logística interna, o que impede a atuação de operadores ferroviários independentes que pretendam atender o mercado interno nacional.

Tendo em vista que ambos os mercados a serem atendidos, externo e interno, possuem sua importância econômica estratégica, analisaram-se possibilidades a serem incorporadas em um modelo de exploração flexível para a renovação das concessões ferroviárias brasileiras, que contemple as possibilidades de autorização aos operadores ferroviários independentes (open access) nos trechos concedidos, e a criação de condições para que empresas privadas sejam autorizadas a explorar trechos ferroviários locais (short-lines), alinhados às políticas públicas para a integração nacional e atendimento ao mercado interno, ratificando assim a importância do papel das ferrovias no fortalecimento e desenvolvimento econômico do Brasil.

\section{REFERÊNCIAS}

AGÊNCIA NACIONAL DE TRANPORTES TERRESTRES - ANTT (a). Concessões ferroviárias. Disponível em: <http://www.antt.gov.br/concessaofer/apresentacaofer.asp>. Acesso em: 23 de maio de 2019.

AGÊNCIA NACIONAL DOS TRANSPORTES TERRESTRES - ANTT (b). Concessões Ferroviárias. $2019 . \quad$ Disponível em <http://www.antt.gov.br/ferrovias/arquivos/Concessoes_Ferroviarias.html>. Acesso em: 23 de maio de 2019.

AGÊNCIA NACIONAL DOS TRANSPORTES TERRESTRES - ANTT (c). Anuário Estatístico. $2019 . \quad$ Disponível em <http://www.antt.gov.br/ferrovias/arquivos/Anuario_Estatistico.html>. Acesso em: Acesso em: 23 de maio de 2019.

ASSIS, A. C. V. et al. Ferrovias de carga brasileiras: uma análise setorial. BNDES Setorial 46/Logística, p. 79 - 126, 2017. 
BANCO NACIONAL DE DESENVOLVIMENTO ECONÔMICO E SOCIAL - BNDES. Privatização no Brasil: 1990-1994/1995-2002. Disponível em: <http://www.bndes.gov.br/SiteBNDES/export/sites/default/bndes_pt/Galerias/Arquivos/conheci mento/pnd/Priv_Gov.PDF>. Acesso em: 26 maio 2019.

CASTRO, N.; LAMY, P. A Reforma e a Modernização do Setor de Transporte Ferroviário de Carga. Rio de Janeiro: IPEA, Texto para Discussão 339, p. 61, 1994.

CONFEDERAÇÃO NACIONAL DO TRANSPORTE - CNT. O Sistema Ferroviário Brasileiro - Transporte e Economia. Brasília, 2013.

DEPARTAMENTO NACIONAL DE INFRAESTRUTURA DE TRANSPORTES - DNIT. Histórico. Disponível em: 〈http://www.dnit.gov.br/ferrovias/historico〉. Acesso em: 25 maio 2019.

KANTINSKY, J. R. Tecnologia e Industrialização. In: Ferrovias Nacionais, São Paulo: UNESP, cap. 2, p. 37-65, 1994.

MARQUES, S. A. Privatização do sistema ferroviário brasileiro. Brasília: IPEA, n. 434, 1996.

MENELAU, B. G. S. Infraestrutura do Transporte Brasileiro: Impactos Sobre o Setor Produtivo, com Ênfase nos Modais Rodoviário e Ferroviário. 2012. 98 f. Dissertação (Mestrado em Economia) - Universidade Federal de Pernambuco, Recife, 2012.

MRS - SA. Estrutura Acionária. Disponível em: $<$ http://ri.mrs.com.br/conteudo_pt.asp?idioma=0\&conta=28\&tipo=54506>. Acesso em: 23 de maio de 2019.

PEIXOTO, J. B. Os Transportes no Atual Desenvolvimento do Brasil. Biblioteca do Exército, v. 147, p 15-19. Rio de Janeiro - RJ, 1977.

REVISTA FERROVIÁRIA. A conta que não fecha. a. 80, p. 36 - 50, Jan - fev 2019.

RUMO. Governança Corporativa: Composição acionária. Disponível em: <http://ri.rumolog.com/ptb/composicao-acionaria>. Acesso em: 23 de maio de 2019.

SOUSA, R. A.; PRATES, H. F. O Processo de Desestatização da RFFSA: principais aspectos e primeiros resultados (1997). Disponível em: <http://www.bndes.gov.br/SiteBNDES/export/sites/default/bndes_pt/Galerias/Arquivos/conheci mento/revista/rev805.pdf>. Acesso em: 26 maio 2019.

VALE. Composição Acionária. Disponível em: <http://www.vale.com/brasil/PT/investors/company/shareholdingstructure/Paginas/default.aspx>. Acesso em: 23 de maio de 2019.

VLI. Conheça a VLI: quem somos. Disponível em: <http://www.vli-logistica.com.br/conhecaa-vli/quem-somos/>. Acesso em: 23 de maio de 2019.

Recebido em: 15/12/2021

Aprovado em: 18/01/2022

Publicado em: 20/01/2022 